\title{
Degradation of fuel oxygenates and their main intermediates by Aquincola tertiaricarbonis L108
}

Correspondence

Roland H. Müller

r.mueller@ufz.de

Received 21 October 2007

Revised 14 February 2008

Accepted 18 February 2008

\author{
Roland H. Müller, ${ }^{1}$ Thore Rohwerder ${ }^{2}$ and Hauke Harms ${ }^{1}$
}

\author{
${ }^{1}$ UFZ, Helmholtz Centre for Environmental Research, Department of Environmental Microbiology, \\ Permoserstr. 15, D-04318 Leipzig, Germany \\ ${ }^{2}$ Aquatic Biotechnology, Biofilm Centre, University Duisburg-Essen, Geibelstr. 41, D-47057 \\ Duisburg, Germany
}

\begin{abstract}
Growth of Aquincola tertiaricarbonis L108 on the fuel oxygenates methyl tert-butyl ether (MTBE), ethyl tert-butyl ether (ETBE) and tert-amyl methyl ether (TAME), as well as on their main metabolites tert-butyl alcohol (TBA), tert-amyl alcohol (TAA) and 2-hydroxyisobutyrate (2-HIBA) was systematically investigated to characterize the range and rates of oxygenate degradation by this strain. The effective maximum growth rates for MTBE, ETBE and TAME at $\mathrm{pH} 7$ and $30{ }^{\circ} \mathrm{C}$ were $0.045 \mathrm{~h}^{-1}, 0.06 \mathrm{~h}^{-1}$ and $0.055 \mathrm{~h}^{-1}$, respectively, whereas TAA, TBA and 2-HIBA permitted growth at rates up to $0.08 \mathrm{~h}^{-1}, 0.1 \mathrm{~h}^{-1}$ and $0.17 \mathrm{~h}^{-1}$, respectively. The experimental growth yields with all these substrates were high. Yields of $0.55 \mathrm{~g}$ dry mass (dm) (g MTBE) ${ }^{-1}$, $0.53 \mathrm{~g} \mathrm{dm}(\mathrm{g} \mathrm{ETBE})^{-1}, 0.81 \mathrm{~g} \mathrm{dm}(\mathrm{g} \mathrm{TAME})^{-1}, 0.48 \mathrm{~g} \mathrm{dm}(\mathrm{g} \mathrm{TBA})^{-1}, 0.76 \mathrm{~g} \mathrm{dm}(\mathrm{g} \mathrm{TAA})^{-1}$ and $0.54 \mathrm{~g} \mathrm{dm}(\mathrm{g} 2-\mathrm{HIBA})^{-1}$ were obtained. Maximum specific degradation rates were $0.92 \mathrm{mmol}$ MTBE $\mathrm{h}^{-1}(\mathrm{~g} \mathrm{dm})^{-1}, 1.11 \mathrm{mmol}$ ETBE $\mathrm{h}^{-1} \mathrm{~g}^{-1}, 0.66 \mathrm{mmol}_{\text {TAME }}{ }^{-1} \mathrm{~g}^{-1}, 1.19 \mathrm{mmol} \mathrm{TAA} \mathrm{h}^{-1}$ $\mathrm{g}^{-1}, 2.82 \mathrm{mmol}$ TBA h${ }^{-1} \mathrm{~g}^{-1}$, and $3.27 \mathrm{mmol} 2$-HIBA $\mathrm{h}^{-1} \mathrm{~g}^{-1}$. The relatively high rates with TBA, TAA and 2-HIBA indicate that the transformations of these metabolites did not limit the metabolism of MTBE and the related ether compounds. Despite the fact that these metabolites still carry a tertiary carbon atom that is commonly suspected to confer recalcitrance to the ether oxygenates, the transformation rates were in the same range as those with succinate and fructose. With MTBE, strain L108 grew at pHs between 5.5 and 8.0 at near-maximal rate, whereas no growth was found below $\mathrm{pH} 5.0$ and above $\mathrm{pH}$ 9.0. The optimum growth temperature was $30{ }^{\circ} \mathrm{C}$, but at $5{ }^{\circ} \mathrm{C}$ still about $15 \%$ of the maximum rate remained, whereas no growth occurred at $42{ }^{\circ} \mathrm{C}$. This indicates that MTBE metabolites are valuable substrates and that $A$. tertiaricarbonis L108 is a good candidate for bioremediation purposes. The possible origin of its exceptional metabolic capability is discussed in terms of the evolution of enzymic activities involved in the conversion of compounds carrying tertiary butyl groups.
\end{abstract}

\section{INTRODUCTION}

Methyl tert-butyl ether (MTBE) and the related compounds ethyl tert-butyl ether (ETBE) and tert-amyl methyl ether (TAME) are widely used as oxygenating compounds in gasoline (Krayer von Krauss \& Harremoës, 2001), leading to pollution by unnoticed leakages and accidental spills (Baehr et al., 1999; Klinger et al., 2002; Schmidt et al., 2002; Squillace et al., 1996). They threaten water resources by their unpleasant odour and taste and suspected carcinogenicity (McGregor, 2006). Consequently, much

Abbreviations: ETBE, ethyl tert-butyl ether; 2-HIBA, 2-hydroxyisobutyric acid; MTBE, methyl tert-butyl ether; TAA, tert-amyl alcohol; TAME, tertamyl methyl ether; TBA, tert-butyl alcohol.

Two supplementary figures showing the influence of temperature and $\mathrm{pH}$ on the growth of $A$. tertiaricarbonis on MTBE are available with the online version of this paper. effort is put into studying the environmental fate of these compounds and developing measures against fuel oxygenate pollution. Microbial degradation has been considered in both respects (Deeb et al., 2000; Fayolle et al., 2001; Schmidt et al., 2004). However, MTBE and structurally related compounds were initially found to withstand microbial attack. This was thought to be mainly due to the ether bond in these compounds and the presence of a tertiary carbon atom.

Generally, it has proved difficult to isolate strains from enrichment cultures using MTBE as sole carbon and energy source. Attempts for more than 15 years were of limited success. At present, there are only a few strains capable of growing solely on oxygenates. These include Methylibium petroleiphilum PM1 (Nakatsu et al., 2006), Methylibium sp. R8 (Rosell et al., 2007), Hydrogenophaga flava ENV735 (Hatzinger et al., 2001), Mycobacterium austroafricanum 
IFP2012 and IFP2015 (François et al., 2002, 2003; Lopes Ferreira et al., 2006), Variovorax paradoxus CL-8 (Zaitsev et al., 2007), and other strains described in little detail (Hernandez-Perez et al., 2001; Lin et al., 2007; Okeke \& Frankenberger, 2003; Pruden \& Suidan, 2004). In addition, we have recently isolated strain L108 from a polluted site in Germany, which is able to grow on MTBE, ETBE and TAME (Rohwerder et al., 2004, 2006) and, like Methylibium petroleiphilum PM1, belongs to the Ideonella-Leptothrix-Rubrivivax branch of the $\beta$-proteobacteria. Strain L108 was classified as a species of a new genus that was named Aquincola tertiaricarbonis (Lechner et al., 2007).

Growth rates on oxygenates are in general low. A mixed culture with $V$. paradoxus CL-8 as the MTBE-degrading entity exhibited a growth rate of $0.012 \mathrm{~h}^{-1}$ (Zaitsev et al., 2007); a rate even one magnitude lower was reported for another mixed culture (Lin et al., 2007). Mycobacterium austroafricanum IFP2012 (François et al., 2002) and IFP2015 (François et al., 2003), Hydrogenophaga flava ENV735 (Hatzinger et al., 2001) and Methylibium petroleiphilum PM1 (Hanson et al., 1999) appeared to utilize MTBE in batch degradation experiments, but specific rates were hardly accessible or even impossible to derive from the published data and indicated difficulties in sustaining growth. Here we report on an examination of the potential of strain L108 to grow on MTBE, ETBE and TAME as sole source of carbon and energy under batch conditions. We also investigated productive, i.e. growth-coupled, degradation of the primary metabolites, viz. tert-butyl alcohol (TBA), tert-amyl alcohol (TAA) and 2-hydroxyisobutyrate (2-HIBA) to identify possible metabolic bottlenecks.

\section{METHODS}

Cultivation. Strain L108 was grown in mineral salts solution containing (in mg l-1): $\mathrm{NH}_{4} \mathrm{Cl}, 760 ; \mathrm{KH}_{2} \mathrm{PO}_{4}, 340 ; \mathrm{K}_{2} \mathrm{HPO}_{4}, 485$; $\mathrm{CaCl}_{2} \cdot 6 \mathrm{H}_{2} \mathrm{O}, 27 ; \mathrm{MgSO}_{4} .7 \mathrm{H}_{2} \mathrm{O}, 71.2$, and $1 \mathrm{ml} \mathrm{l}^{-1}$ of trace element solution; the trace element solution was composed of (in $\mathrm{g}^{-1}$ ): $\mathrm{FeSO}_{4} .7 \mathrm{H}_{2} \mathrm{O}, 4.98 ; \mathrm{CuSO}_{4} .5 \mathrm{H}_{2} \mathrm{O}, 0.785 ; \mathrm{CoCl}_{2}, 5 ; \mathrm{MnSO}_{4} .4 \mathrm{H}_{2} \mathrm{O}, 0.81$; $\mathrm{ZnSO}_{4} .7 \mathrm{H}_{2} \mathrm{O}, 0.44 ; \mathrm{Na}_{2} \mathrm{MoO}_{4} \cdot 2 \mathrm{H}_{2} \mathrm{O}, 0.25$. The medium was supplemented with a vitamin mixture to final concentrations of (in $\mu \mathrm{g} \mathrm{l}^{-1}$ ): biotin, 20; folic acid, 20; pyridoxine. $\mathrm{HCl}, 100$; thiamine. $\mathrm{HCl}, 50$; riboflavin, 50; nicotinic acid, 50; calcium DL-pantothenate, 50; $p$ aminobenzoic acid, 50; lipoic acid, 50; and cobalamin, 50.

The strain was inoculated into $200 \mathrm{ml}$ mineral salts solution to give an initial biomass concentration of about $25 \mathrm{mg}$ dry mass $\mathrm{l}^{-1}$. Incubation was performed in $600 \mathrm{ml}$ bottles, closed with gas-tight butyl rubber stoppers, on a rotary shaker at 150 r.p.m. at $30{ }^{\circ} \mathrm{C}$. The initial $\mathrm{pH}$ was 7.0 and was not corrected throughout the experiment. Liquid samples were taken at various times by a sterile syringe puncturing the butyl rubber stopper. Specific growth rates were derived from the linear part of semi-logarithmic plots of the biomass concentration versus time by regression analysis. The kinetic parameters were derived from double-reciprocal plots of rates versus substrate concentrations to obtain the apparent, experimentally relevant values or by nonlinear regression (Haldane equation) to obtain kinetically based parameters according to

$\mu=\mu_{\max } \times S /\left[K_{\mathrm{s}}+\left(1+S / K_{\mathrm{i}}\right) \times S\right]$
Analytics. Biomass was determined as $\mathrm{OD}_{700}$. $\mathrm{OD}_{700}$ multiplied by a factor of $0.54 \pm 0.03$ was found to give the dry mass in $\mathrm{mg} \mathrm{ml}^{-1}$. MTBE, ETBE, TAME, TAA and TBA were determined by head-space gas chromatography as previously described (Rohwerder et al., 2006). 2-HIBA was determined by gas chromatography as the methyl ester according to a procedure given elsewhere (Rohwerder et al., 2006). Fructose, lactate, pyruvate and succinate were measured by HPLC at an oven temperature of $70{ }^{\circ} \mathrm{C}$ using an Ion $300 \mathrm{OA}$ column (Macherey Nagel). The mobile phase was $0.005 \mathrm{M} \mathrm{H}_{2} \mathrm{SO}_{4}$ fed with a rate of $0.6 \mathrm{ml} \mathrm{min}{ }^{-1}$; detection was by refractive index (RID). The compounds measured by the various methods were detected with $95 \%$ confidence.

MTBE, ETBE, lactate, pyruvate and succinate (sodium salts) and fructose were purchased from Merck; TAME and other chemicals used were obtained from Fluka.

\section{RESULTS}

The growth kinetics of strain L108 in batch culture on MTBE, ETBE and TAME and on the major metabolites TBA, TAA and 2-HIBA are shown in Figs 1 and 2, respectively. With MTBE, the maximum specific growth rate, $\mu_{\max }$, was reached at a concentration around $2.5 \mathrm{mM}$. Data treatment at this concentration range in a doublereciprocal plot revealed a $\mu_{\max }$ of $0.047 \mathrm{~h}^{-1}$ and $K_{\mathrm{s}}$ of $0.59 \mathrm{mM}$. Higher concentrations resulted in inhibition that

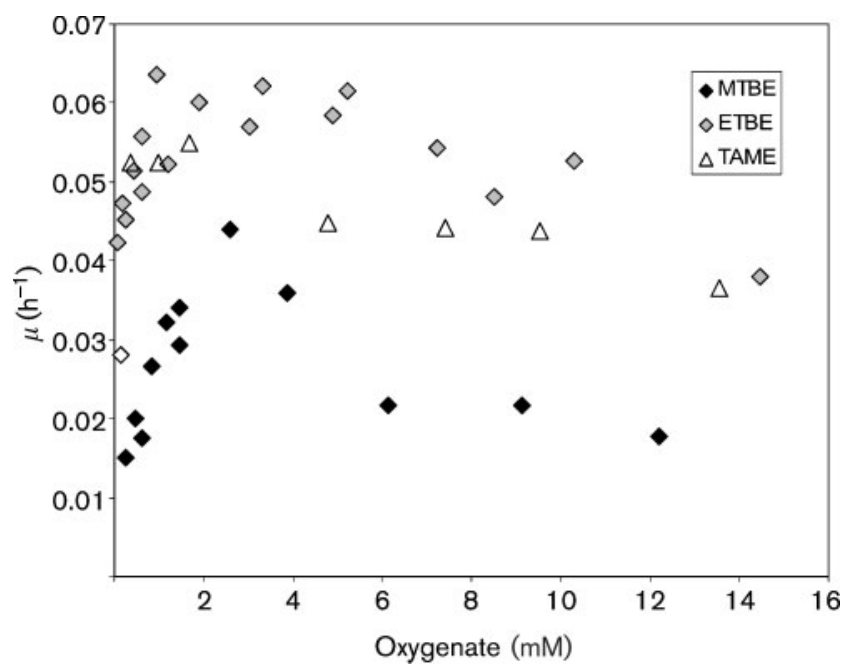

Fig. 1. Growth kinetics of $A$. tertiaricarbonis L108 on MTBE, ETBA, and TAME. The flasks were tightly closed with butyl rubber stoppers to avoid loss of the substrates by volatilization. The ratio of liquid to air volume was calculated to guarantee oxygen sufficient for complete aerobic degradation of MTBE. Incubation was performed at $30{ }^{\circ} \mathrm{C}$ and an initial $\mathrm{pH}$ value of 7.0 with shaking at 150 r.p.m. Samples were taken by a syringe via the butyl rubber stoppers. Biomass was measured as $\mathrm{OD}_{700}$ immediately after taking the samples. Growth rates were derived by linear regression from semi-logarithmic plots of $\mathrm{OD}_{700}$ versus time. Samples for substrate measurement were prepared as indicated by Rohwerder et al. (2006). The values on the $x$-axis indicate the initial substrate concentration in the liquid medium. 


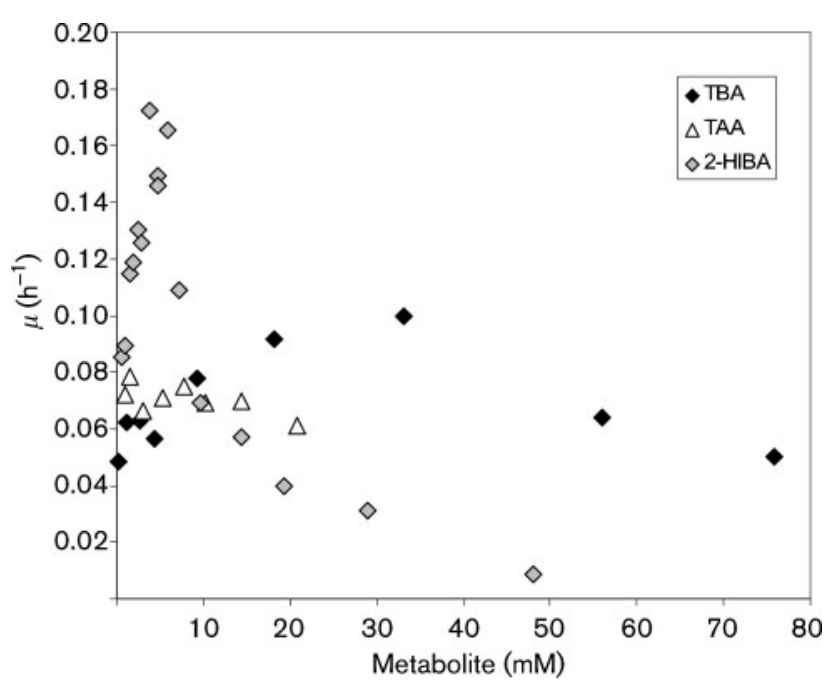

Fig. 2. Growth kinetics of $A$. tertiaricarbonis L108 on TBA, TAA and 2-HIBA. For further details see legend to Fig. 1.

levelled off at about $50 \%$ of the maximum rate above $6 \mathrm{mM}$. The above values correspond to the apparent but finally effective kinetic parameters. Inclusion of nonlinear regression analysis by using equation 1 resulted in kinetically more sound parameters. With MTBE as a substrate these amounted to $\mu_{\max }=0.097 \mathrm{~h}^{-1}$, $K_{\mathrm{s}}=1.86 \mathrm{mM}$ and $K_{\mathrm{i}}=7.0 \mathrm{mM}$. With ETBE, an effective $\mu_{\max }$ of around $0.06 \mathrm{~h}^{-1}$ was obtained, with only slight inhibition appearing at higher concentrations (Fig. 1). Nonlinear regression revealed $\mu_{\max }=0.065 \mathrm{~h}^{-1}$, $K_{\mathrm{s}}=0.089 \mathrm{mM}$ and $K_{\mathrm{i}}=35.0 \mathrm{mM}$. Due to the quotient of $\mu_{\max } / K_{\mathrm{s}}$ (specific affinity; Healey 1980), ETBE ( $\mu_{\max } /$ $\left.K_{\mathrm{s}}=0.73 \mathrm{~h}^{-1} \mathrm{mM}^{-1}\right)$ was a significantly better substrate for strain L108 than MTBE $\left(\mu_{\max } / K_{\mathrm{s}}=0.052 \mathrm{~h}^{-1} \mathrm{mM}^{-1}\right)$. TAME was apparently a better growth substrate than MTBE also. The $\mu_{\max }$ of $0.055 \mathrm{~h}^{-1}$ was reached already at a TAME concentration of $0.35 \mathrm{mM}$. The growth rate levelled off between 5 and $10 \mathrm{mM}$ before slightly decreasing at higher concentrations until approaching zero at $32 \mathrm{mM}$ (data not shown). Due to the higher affinity to TAME, our rate data did not allow calculation of reliable $K_{\mathrm{s}}$ values with this substrate. Because of problems in verifying growth at these low concentrations, experiments were not performed at such substrate levels.

Growth on TAA (Fig. 2) gave a $\mu_{\max }$ of $0.08 \mathrm{~h}^{-1}$ at a substrate concentration of $1 \mathrm{mM}$ and this decreased only slightly to $0.07 \mathrm{~h}^{-1}$ towards the highest tested concentration of $20 \mathrm{mM}$. The affinity to TBA was the lowest among all tested growth substrates although exact affinities could not be derived from the present data. A $\mu_{\max }$ of $0.1 \mathrm{~h}^{-1}$ was obtained at about $35 \mathrm{mM}$ (Fig. 2). At higher concentrations the activity decreased to about half of the maximum rate at about $75 \mathrm{mM}$ and stopped at $200 \mathrm{mM}$ (not shown). The fastest growth was obtained with 2-HIBA. Doublereciprocal data analysis revealed an apparent $\mu_{\max }$ of $0.19 \mathrm{~h}^{-1}$, obtained at around $5 \mathrm{mM}$ substrate, followed by rather pronounced inhibition to $20 \%$ of $\mu_{\max }$ at $29 \mathrm{mM}$. The apparent $K_{\mathrm{s}}$ for 2-HIBA derived in the same way was $1.05 \mathrm{mM}$. With nonlinear regression we obtained $\mu_{\max }=0.305 \mathrm{~h}^{-1}, K_{\mathrm{s}}=1.6 \mathrm{mM}$ and $K_{\mathrm{i}}=7.0 \mathrm{mM}$ by using equation 1.

Table 1 lists all values of $\mu_{\max }$ together with the corresponding yield coefficients, $Y$, that were derived from biomass formation after substrate exhaustion and maximum specific substrate consumption rates, $q_{\mathrm{s}}=\mu Y^{-1}$. Values obtained with the common substrates pyruvate, succinate, lactate and fructose were included as references for comparison. Yields with the oxygenates and their metabolites were around or above $0.5 \mathrm{~g}$ biomass (g substrate $)^{-1}$, with the highest yields of around $0.8 \mathrm{~g} \mathrm{~g}^{-1}$ obtained with TAME and TAA. These values are about twice as high as those obtained with the reference substrates and reflect the more reduced state of the former. The rates of growth and consumption of oxygenates and metabolites were between 2 and 10 times slower than those with the reference substrates. Particularly, growth with

Table 1. Growth parameters and productivity of substrate consumption obtained with $A$. tertiaricarbonis strain L108

\begin{tabular}{|c|c|c|c|}
\hline Substrate & $\mu_{\max }\left(\mathrm{h}^{-1}\right)^{*}$ & $Y, \mathrm{~g} \mathrm{~mol}^{-1}\left(\mathrm{~g} \mathrm{~g}^{-1}\right)$ & $q_{\mathrm{s}}, \mathrm{mmol} \mathrm{g}^{-1} \mathrm{~h}^{-1}\left(\mathrm{mg} \mathrm{g}^{-1} \mathrm{~h}^{-1}\right)$ \\
\hline MTBE & 0.045 & $48.8 \pm 4.4(0.55 \pm 0.05)$ & $0.92(81)$ \\
\hline ETBE & 0.06 & $54.1 \pm 2.0(0.53 \pm 0.02)$ & $1.11(113)$ \\
\hline TAME & 0.055 & $83.0 \pm 4.0(0.81 \pm 0.05)$ & $0.66(68)$ \\
\hline TBA & 0.1 & $35.5 \pm 2.2(0.48 \pm 0.03)$ & $2.82(208)$ \\
\hline TAA & 0.08 & $67.0 \pm 7.0(0.76 \pm 0.08)$ & $1.19(105)$ \\
\hline 2-HIBA & 0.17 & $52.0 \pm 2.0(0.50 \pm 0.02)$ & $3.54(340)$ \\
\hline Lactate & 0.299 & $34.4 \pm 1.0(0.38 \pm 0.01)$ & $8.69(790)$ \\
\hline Pyruvate & 0.314 & $25.3 \pm 1.2(0.29 \pm 0.01)$ & $12.4(1090)$ \\
\hline Succinate & 0.318 & $38.3 \pm 1.2(0.32 \pm 0.02)$ & $8.3(980)$ \\
\hline Fructose & 0.242 & $56.6 \pm 0.8(0.31 \pm 0.04)$ & $4.28(770)$ \\
\hline
\end{tabular}

${ }^{\star}$ Experimental maximum. 
2-HIBA approached the rates obtained with the reference substrates. There was a general trend that the oxygenate metabolites were consumed faster than the mother compounds. This seems to indicate that later stages of the metabolism did not control the rates of oxygenate consumption. Nevertheless, during growth on MTBE and ETBE, TBA concentrations between 3 and $5 \mu \mathrm{M}$ were always released into the cultivation broth. In addition, similar amounts of the TBA precursor tert-butyl formate were detected when strain L108 was cultivated on MTBE. In contrast, the corresponding esters tert-butyl acetate and tert-amyl formate were not detectable in cultures growing on ETBE and TAME, respectively. In summary, it appears that oxygenate intermediates such as TBA and 2-HIBA, which were previously supposed to be recalcitrant, are substrates almost as good as succinate or fructose for strain L108.

As strain L108 was isolated from an aquifer and hence could be valuable for groundwater remediation, we investigated the influence of temperature and $\mathrm{pH}$ on its growth on MTBE. The maximum rate was obtained at $30{ }^{\circ} \mathrm{C}$ and dropped to about $50 \%$ at $37{ }^{\circ} \mathrm{C}$, whereas no growth was observed at $42{ }^{\circ} \mathrm{C}$. At $12{ }^{\circ} \mathrm{C}$, only $10 \%$ of the maximum rate remained (see Supplementary Fig. S1, available with the online version of this paper). Surprisingly, the rate rose significantly when the temperature dropped further $\left(0.012 \pm 0.0035 \mathrm{~h}^{-1}\right.$ at $5{ }^{\circ} \mathrm{C}$ vs $0.005 \pm 0.0013 \mathrm{~h}^{-1}$ at $\left.12{ }^{\circ} \mathrm{C} ; n=3\right)$. Growth continued below $5{ }^{\circ} \mathrm{C}$ but was difficult to control; hence the data were not included in Fig. S1. Strain L108 was active over a wide $\mathrm{pH}$ range: a plateau of almost constant maximum growth rate extended from $\mathrm{pH} 5.5$ to 8 . Beyond this range, there was a rapid decline in growth rate, with no growth at either pH 5 or pH 9 (Supplementary Fig. S2).

\section{DISCUSSION}

Batch growth studies over a wide range of substrate concentrations made it evident that A. tertiaricarbonis L108 (Rohwerder et al., 2006) is very effective in the productive degradation of all three common fuel oxygenates MTBE, ETBE and TAME. An effective maximum growth rate of about $0.045 \mathrm{~h}^{-1}$ with MTBE and up to $20 \%$ higher ones with ETBE and TAME were found. Growth rates on the MTBE and ETBE metabolites TBA and 2-HIBA even amounted to $0.1 \mathrm{~h}^{-1}$ and $0.17 \mathrm{~h}^{-1}$, respectively. These high growth rates approach rates obtained with common substrates such as fructose or succinate, indicating that fuel oxygenate metabolism in strain L108 is well established.

Hence, the strain has attained a metabolic capacity that is clearly beyond the level of fortuitous enzyme activity but suggests elevated substrate specificity. The former statement refers to the observation that the conversion of a pollutant is often catalysed by defined enzymes in an unspecific manner, resulting in low rates due to the xenobiotic structure of the compounds (Janssen et al.,
2005). Although the oxygenate degradation pathway(s) have not been elucidated completely, three important steps have already been identified in strain L108. The initial monooxygenase reaction attacking both the methyl and ethyl groups of MTBE and ETBE, respectively, is catalysed by a cytochrome P450-type enzyme encoded by the eth $A B C D$ genes (Breuer et al., 2007). A similar monooxygenase has been previously detected in Rhodococcus ruber IFP2001 growing on ETBE (Chauvaux et al., 2001). A different oxygenase system, which has similarity to phthalate dioxygenase, is likely responsible for hydroxylating TBA in strain L108 (Schäfer et al., 2007). The metabolite 2-HIBA is converted by a novel cobalamindependent mutase to 3-hydroxybutyrate (Rohwerder et al., 2006). Thus far, this combination of specific enzymes has not been found in other oxygenate-degrading strains. Recently, a monooxygenase of the AlkB type has been described for Mycobacterium austroafricanum IFP2012 (Lopes Ferreira et al., 2007), supposed to hydroxylate both MTBE and TBA. Hydroxylation of the latter is inhibited by MTBE, resulting in the accumulation of TBA in strain IFP2012 (François et al., 2002, 2003). For Methylibium petroleiphilum PM1, a phthalate dioxygenase-like enzyme and a mutase very similar to the enzymes found in strain L108 have been recently proposed for TBA hydroxylation and 2-HIBA isomerization, respectively (Hristova et al., 2007). However, eth $A B C D$ is not present in the genome of strain PM1 (Kane et al., 2007). Consequently, at least the initial steps in MTBE degradation deviate in strains PM1 and L108, obviously resulting in different capacities for growth on ether oxygenates such as MTBE and ETBE. The pathway for TAME degradation has not been elucidated so far. Proposing similarity with the pathways for MTBE and ETBE, tert-amyl formate and TAA would be intermediates. The latter could be converted to 3-hydoxyisovaleric acid and then split into acetone and acetyl-CoA (NemecekMarshall et al., 1999). However, due to the inability of strain L108 to grow on acetone (Lechner et al., 2007), a cobalamin-dependent route via 2-hydroxy-2-methylbutyrate, corresponding to the TBA intermediate 2-HIBA, is more likely.

A comparison of the capacities of various described strains to degrade MTBE and some key intermediates shows that strain L108 is apparently effective (Table 2). Only Variovorax sp. strain JV-1 appears to have a similar potential for the degradation of MTBE (Uotila \& Zaitsev, 2003). Obviously, this strain is equipped with a set of specific enzymes as efficient as the one found in strain L108. For most of other strains besides those included in the table, reported information did not allow derivation of $q_{\mathrm{s}}$ values for MTBE. Although not always obvious, this may indicate that MTBE degradation was at best weakly coupled to growth in these bacteria, e.g. strains IFP 2012, PM1 and ENV735. With TBA as the substrate, the specific degradation rates of strain L108 were in each case significantly above those found with the other strains (Table 2). This was also true for 2-HIBA except for strain CIP I-2052, 
Table 2. Comparison of microbial strains for their specific capacity to degrade MTBE and its main degradation products

\begin{tabular}{|c|c|c|c|c|}
\hline Substrate & Strain & $q_{s}\left(\mathrm{mmol} \mathrm{g}^{-1} \mathrm{~h}^{-1}\right)$ & Remarks* & Reference \\
\hline \multirow[t]{3}{*}{ MTBE } & A. tertiaricarbonis L108 & 0.92 & SC & This work \\
\hline & Variovorax sp. JV-1 & 0.69 & $22{ }^{\circ} \mathrm{C}$ & Uotila \& Zaitsev (2003) \\
\hline & Variovorax paradoxus CL-8 & 0.39 & $22{ }^{\circ} \mathrm{C}$ & Zaitsev et al. (2007) \\
\hline \multirow[t]{7}{*}{ TBA } & A. tertiaricarbonis $\mathrm{L} 108$ & 2.82 & SC & This work \\
\hline & A. tertiaricarbonis $\mathrm{L} 10$ & 2.02 & $5 \mathrm{mM} \dagger$ & Rohwerder et al. (2006) \\
\hline & A. tertiaricarbonis L10 & 1.65 & $\operatorname{Co} \neq$ & Rohwerder et al. (2006) \\
\hline & Variovorax sp. CL-3 & 0.96 & $28{ }^{\circ} \mathrm{C}$ & Uotila \& Zaitsev (2003) \\
\hline & Variovorax paradoxus CL-8 & 0.94 & $22{ }^{\circ} \mathrm{C}$ & Zaitsev et al. (2007) \\
\hline & A. tertiaricarbonis CIP I-2052 & 0.80 & $\operatorname{Co} \ddagger$ & Piveteau et al. (2001) \\
\hline & Mycobacterium austroafricanum IFP 2012 & 0.86 & Co末 & François et al. (2002) \\
\hline \multirow[t]{7}{*}{ 2-HIBA } & A. tertiaricarbonis $\mathrm{L} 108$ & 3.27 & SC & This work \\
\hline & A. tertiaricarbonis $\mathrm{L} 10$ & 2.93 & $10 \mathrm{mM}$ & Rohwerder et al. (2006) \\
\hline & A. tertiaricarbonis $\mathrm{L} 10$ & 1.21 & $\operatorname{Co} \ddagger$ & Rohwerder et al. (2006) \\
\hline & Variovorax paradoxus CL-8 & 0.95 & $22{ }^{\circ} \mathrm{C}$ & Zaitsev et al. (2007) \\
\hline & A. tertiaricarbonis CIP I-2052 & 2.53 & SC & Rohwerder et al. (2006) \\
\hline & A. tertiaricarbonis CIP I-2052 & 1.11 & $\operatorname{Co} \neq$ & Rohwerder et al. (2006) \\
\hline & Mycobacterium austroafricanum IFP 2012 & 1.35 & SC & François et al. (2002) \\
\hline
\end{tabular}

${ }^{\star}$ Deviations from standard conditions (sc) are indicated. Standard conditions applied in this study included: incubation at $30{ }^{\circ} \mathrm{C}$ and initial $\mathrm{pH}$ value of 7.0, as well as the presence of vitamin $\mathrm{B} 12$ in addition to $\mathrm{Co}^{2+}$.

$\dagger$ Actual substrate concentration (cf. Fig. 2).

¥Incubation in the presence of $\mathrm{Co}^{2+}$ but omitting vitamin $\mathrm{B} 12$.

which achieved similarly high rates. For strains L10 and CIP I-2052, it has been demonstrated that growth rates on TBA and 2-HIBA significantly decreased when cobalamin was replaced by cobalt ions in the growth medium (Table 2). This phenomenon may be due to the effort in synthesizing cobalamin required for the mutase pathway, converting 2-HIBA into 3-hydroxybutyrate (Rohwerder \& Müller, 2007). Although the cobalt dependency of strain IFP2012 for degrading MTBE and its metabolites (François et al., 2002) indicates 2-HIBA mutase activity also in this strain, slower consumption of TBA and 2-HIBA in the presence of cobalamin may be caused by incapacity of taking up the externally added vitamin.

MTBE and ETBE are potent heterotrophic substrates due to their reduced state, as was shown in a theoretical study (Müller et al., 2007). Experimental yields of $\geqslant 0.5 \mathrm{~g} \mathrm{~g}^{-1}$ prove the effective use of these substrates for the growth and multiplication of strain L108. A similar yield coefficient of $0.49 \mathrm{~g} \mathrm{~g}^{-1}$ was obtained with Variovorax paradoxus CL-8 (Zaitsev et al., 2007). For Mycobacterium austroafricanum IFP2012, yields of $0.44 \mathrm{~g} \mathrm{~g}^{-1}$ (MTBE), $0.61 \mathrm{~g} \mathrm{~g}^{-1}$ (TBA) and $0.42 \mathrm{~g} \mathrm{~g}^{-1}$ (2-HIBA) were reported (François et al., 2002). Biomass synthesis may, however, be nil or even negative at very low rates of substrate consumption (Müller et al., 2007). The enrichment of MTBE-degrading cultures under such conditions indicates that the maintenance requirements are modest in these strains, which may be either an intrinsic property of such strains or an adaptation of productive MTBE degraders. The difficulty of enriching degradative strains in the early years of MTBE research or the need to provide them with auxiliary substrates such as n-alkanes (Haase et al., 2006; Steffan et al., 1997) may be an indication of the recent acquisition of the regulatory and enzymic capacity to use MTBE as sole carbon and energy source.

Interestingly, the ether-related metabolites, namely TBA, 2HIBA and TAA, are better substrates than the mother compounds. This raises questions about the evolution of the degradation pathways. MTBE and related ethers have been only recently introduced into nature, since their massive use as fuel additives began only in the late 1980s (Squillace et al., 1997). In contrast, oxygenate-independent sources are known for the tertiary alcohols and 2-HIBA (Fig. 3). 2-HIBA is a by-product of the classical methacrylate synthesis process via 2-hydroxyisobutyronitrile (Rohwerder et al., 2006), which started in the mid1930s. This may explain why Holowach and coworkers reported already in 1994 the isolation of 2-HIBA-converting bacterial strains from the wastewater of a methacrylateproducing plant (Holowach et al., 1994). In addition, 2hydroxyisobutyronitrile is a degradation product of the plant cyanoglycoside linamarin (Forslund et al., 2004) and can form 2-HIBA in the presence of nitrilase or nitrile hydratase and amidase activity (Banerjee et al., 2002). A third ether-independent 2-HIBA source could be the conversion of isobutene via the corresponding 1,2-epoxide and 2-hydroxy-2-methylpropanol (Rohwerder \& Müller, 2007). Likewise, Hyman and co-workers have recently questioned whether MTBE and ETBE are the only source for TBA (Hyman et al., 2007). Indeed, it has been reported 


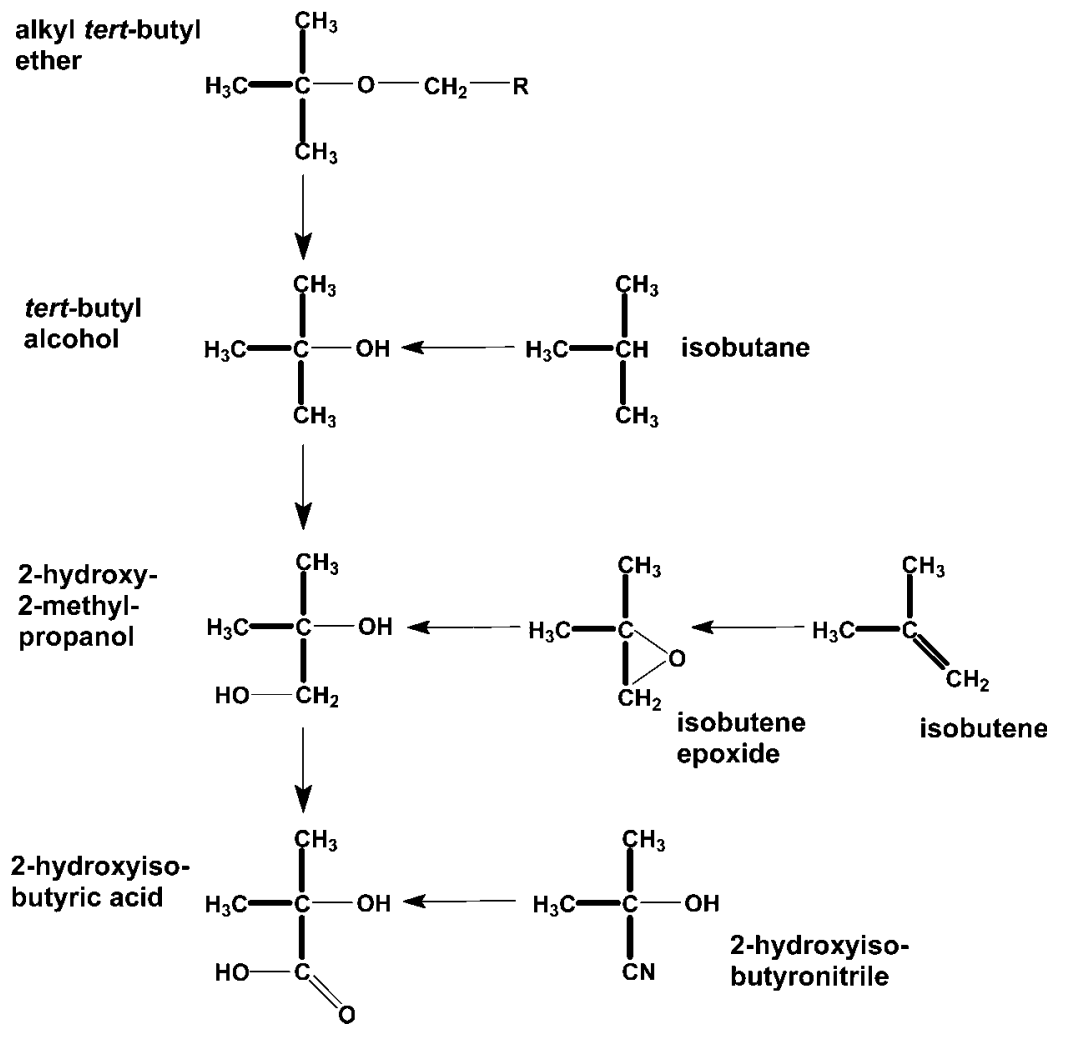

Fig. 3. Potential substrates and routes involved in the evolution of degradative capabilities for MTBE and related compounds.

several times that the activity of methane monooxygenase and other alkane monooxygenases on isobutane, isopentane and homologous hydrocarbons not only resulted in the corresponding primary and secondary alcohols but also formed the tertiary ones (Dubbels et al., 2007; Imai et al., 1986; Onodera et al., 1990; Patel et al., 1982). Hence, although growth on 2-HIBA and tertiary alcohols was not reported before man started ether oxygenate production, their degradation pathways could have evolved far earlier and totally independent of ether oxygenate contamination (Fig. 3).

\section{ACKNOWLEDGEMENTS}

The authors are grateful to Cornelia Schumann for excellent technical support and to Dr Luis Samaniego for help in nonlinear regression analysis.

\section{REFERENCES}

Baehr, A. I., Stackelberg, P. E. \& Baker, R. J. (1999). Evaluation of the atmosphere as a source of volatile organic compounds in shallow groundwater. Water Resour Res 35, 127-136.

Banerjee, A., Sharma, R. \& Banerjee, U. C. (2002). The nitriledegrading enzymes: current status and future prospects. Appl Microbiol Biotechnol 60, 33-44.

Breuer, U., Bäjen, C., Rohwerder, T., Müller, R. H. \& Harms, H. (2007). MTBE degradation genes of an Ideonella-like bacterium L108. In Proceedings of the 3rd European Conference on MTBE and Other Fuel Oxygenates, p. 103. Antwerp, Belgium: VITO.
Chauvaux, S., Chevalier, F., Le Dantec, C., Fayolle, F., Miras, I., Kunst, F. \& Beguin, P. (2001). Cloning of a genetically unstable cytochrome P-450 gene cluster involved in degradation of the pollutant ethyl tert-butyl ether by Rhodococcus ruber. J Bacteriol 183, 6551-6557.

Deeb, R. A., Scow, K. M. \& Alvarez-Cohen, L. (2000). Aerobic MTBE biodegradation: an examination of past studies, current challenges and future research directions. Biodegradation 11, 171-186.

Dubbels, B. L., Sayavedra-Soto, L. \& Arp, D. J. (2007). Butane monooxygenase of 'Pseudomonas butanovora': purification and biochemical characterization of a terminal-alkane hydroxylating diiron monooxygenase. Microbiology 153, 1808-1816.

Fayolle, F., Vandecasteele, J. P. \& Monot, F. (2001). Microbial degradation and fate in the environment of methyl tert-butyl ether and related fuel oxygenates. Appl Microbiol Biotechnol 56, 339-349.

Forslund, K., Morant, M., Jørgensen, B., Olsen, C. E., Asamizu, E., Sato, S., Tabata, S. \& Bak, S. (2004). Biosynthesis of the nitrile glucosides rhodiocyanoside A and D and the cyanogenic glucosides lotaustralin and linamarin in Lotus japonicus. Plant Physiol 135, 71-84.

François, A., Mathis, H., Godefroy, D., Piveteau, P., Fayolle, F. \& Monot, F. (2002). Biodegradation of methyl tert-butyl ether and other fuel oxygenates by a new strain, Mycobacterium austroafricanum IFP 2012. Appl Environ Microbiol 68, 2754-2762.

François, A., Garnier, L., Mathis, H., Fayolle, F. \& Monot, F. (2003). Roles of tert-butyl formate, tert-butyl alcohol and acetone in the regulation of methyl tert-butyl ether degradation by Mycobacterium austroafricanum IFP 2012. Appl Microbiol Biotechnol 62, 256-262.

Haase, K., Wendlandt, K. D., Gräber, A. \& Stottmeister, U. (2006). Cometabolic degradation of MTBE using methane-, propane-, and butane-utilizing enrichment cultures and Rhodococcus sp. BU3. Eng Life Sci 6, 508-513. 
Hanson, J. R., Ackerman, C. E. \& Scow, K. M. (1999). Biodegradation of methyl tert-butyl ether by a bacterial pure culture. Appl Environ Microbiol 65, 4788-4792.

Hatzinger, P. B., McClay, K., Vainberg, S., Tugusheva, M., Condee, C. W. \& Steffan, R. J. (2001). Biodegradation of methyl tert-butyl ether by a pure bacterial culture. Appl Environ Microbiol 67, 5601-5607.

Healey, F. P. (1980). Slope of the Monod equation as an indicator of advantage in nutrient competition. Microb Ecol 5, 281-286.

Hernandez-Perez, G., Fayolle, F. \& Vandecasteele, J.-P. (2001). Biodegradation of ethyl tert-butyl ether (ETBE), methyl tert-butyl ether (MTBE) and tert-amyl methyl ether (TAME) by Gordonia terrae. Appl Microbiol Biotechnol 55, 117-121.

Holowach, L. P., Swift, G. W., Wolk, S. W. \& Klawiter, L. (1994). Bacterial conversion of a waste stream containing methyl-2-hydroxyisobutyric acid to biodegradable polyhydroxyalkanoate polymers. In Polymers from Agricultural Coproducts, pp. 202-211. Edited by M. L. Fishman, R. B. Friedman \& S. J. Huang. ASC Symposium Series 575. Washington, DC: ACS

Hristova, K. R., Schmidt, R., Chakicherla, A. Y., Legler, T. C., Wu, J., Chain, P. S., Scow, K. M. \& Kane, S. R. (2007). Comparative transcriptome analysis of Methylibium petroleiphilum PM1 exposed to the fuel-oxygenates methyl-tert-butyl ether and ethanol. Appl Environ Microbiol 73, 7347-7357.

Hyman, M., Aslett, D., Golant, K. \& Jones, J. (2007). Microbial production and consumption of tertiary butyl alcohol. In Proceedings of the 3rd European Conference on MTBE and Other Fuel Oxygenates, p. 82. Antwerp, Belgium: VITO.

Imai, T., Takigawa, H., Nakagawa, S., Shen, G.-J., Kodama, T. \& Minoda, Y. (1986). Microbial oxidation of hydrocarbons and related compounds by whole-cell suspensions of the methane-oxidizing bacterium H-2. Appl Environ Microbiol 52, 1403-1406.

Janssen, D. B., Dinkla, I. J. T., Poelarends, G. J. \& Terpstra, P. (2005). Bacterial degradation of xenobiotic compounds: evolution and distribution of novel enzyme activities. Environ Microbiol 7, 1868-1882.

Kane, S. R., Chakicherla, A. Y., Chain, P. S., Schmidt, R., Shin, M. W., Legler, T. C., Scow, K. M., Larimer, F. W., Lucas, S. M. \& other authors (2007). Whole-genome analysis of the methyl tert-butyl ether-degrading beta-proteobacterium Methylibium petroleiphilum PM1. J Bacteriol 189, 1931-1945.

Klinger, J., Stiehler, C., Sacher, F. \& Branch, H. J. (2002). MTBE (methyl tertiary-butyl ether) in groundwaters: monitoring results from Germany. J Environ Monit 4, 276-279.

Krayer von Krauss, M. \& Harremoës, P. (2001). MTBE in petrol as a substitute for lead. In Late Lessons from Early Warning: The Precautionary Principle 1896-2000. Environmental Issue Report, vol. 22. Edited by P. Harremoës. Copenhagen: Office for Official Publications of the European Community.

Lechner, U., Brodkorb, D., Geyer, R., Hause, G., Härtig, C., Auling, G., Fayolle-Guichard, F., Piveteau, R., Müller, R. H. \& Rohwerder, T. (2007). Aquincola tertiaricarbonis gen. nov., sp. nov., a tertiary butyl moiety-degrading bacterium. Int J Syst Evol Microbiol 57, 1295-1303.

Lin, C.-W., Tsai, S.-L. \& Hou, S.-H. (2007). Effects of environmental settings on MTBE removal for a mixed culture and its monoculture isolation. Appl Microbiol Biotechnol 74, 194-201.

Lopes Ferreira, N., Maciel, H., Mathis, H., Monot, F., FayolleGuichard, F. \& Greer, C. W. (2006). Isolation and characterization of a new Mycobacterium austroafricanum strain, IFP 2015, growing on MTBE. Appl Microbiol Biotechnol 70, 358-365.

Lopes Ferreira, N., Mathis, H., Labbé, D., Monot, F., Greer, C. W. \& Fayolle-Guichard, F. (2007). n-Alkane assimilation and tert-butyl alcohol (TBA) oxidation capacity in Mycobacterium austroafricanum strains. Appl Microbiol Biotechnol 75, 909-919.
McGregor, D. (2006). Methyl tertiary-butyl ether: studies for potential human health hazards. Crit Rev Toxicol 36, 319-358.

Müller, R. H., Rohwerder, T. \& Harms, H. (2007). Carbon conversion efficiency and limits of productive bacterial degradation of methyl tert-butyl ether and related compounds. Appl Environ Microbiol 73, 1783-1791.

Nakatsu, C. H., Hristova, K., Hanada, S., Meng, X.-Y., Hanson, J., Scow, K. M. \& Kamagata, Y. (2006). Methylibium petroleiphilum $\mathrm{PM1}^{\mathrm{T}}$ gen. nov., sp. nov., a new methyl tert-butyl ether (MTBE) degrading methylotroph of the beta-Proteobacteria. Int J Syst Evol Microbiol 56, 983-989.

Nemecek-Marshall, M., Wojciechowski, C., Wagner, W. P. \& Fall, R. (1999). Acetone formation in the Vibrio family: a new pathway for bacterial leucine catabolism. J Bacteriol 181, 7493-7499.

Okeke, B. C. \& Frankenberger, W. T., Jr (2003). Biodegradation of methyl tertiary butyl ether (MTBE) by a bacterial enrichment consortium and its monoculture isolates. Microbiol Res 158, 99-106.

Onodera, M., Sakai, H., Endo, Y. \& Ogasawara, N. (1990). Oxidation of short-chain iso-alkanes by gaseous hydrocarbon assimilating mold, Scedosporium sp. A-4. Agric Biol Chem 54, 2413-2416.

Patel, R. N., Hou, C. T., Laskin, A. I. \& Felix, A. (1982). Microbial oxidation of hydrocarbons: properties of a soluble methane monooxygenase from a facultative methane-utilizing organism, Methylobacterium sp. strain CRL-26. Appl Environ Microbiol 44, 1130-1137.

Piveteau, P., Fayolle, F., Vandecasteele, J. P. \& Monot, F. (2001). Biodegradation of tert-butyl alcohol and related xenobiotics by a methylotrophic bacterial isolate. Appl Microbiol Biotechnol 55, 369-373.

Pruden, A. \& Suidan, M. (2004). Effect of benzene, toluene, ethylbenzene, and $p$-xylene (BTEX) mixture on biodegradation of methyl tert-butyl ether (MTBE) and tert-butyl alcohol (TBA) by a pure culture UC1. Biodegradation 15, 213-227.

Rohwerder, T. \& Müller, R. H. (2007). New bacterial cobalamindependent CoA-carbonyl mutases involved in degradation pathways. In Vitamin B Research Advances, pp. 81-98. Edited by C. M. Elliot. New York: Nova Science Publishers.

Rohwerder, T., Cenini, V., Held, C., Martienssen, M., Lechner, U. \& Müller, R. H. (2004). Novel MTBE-degrading bacterial isolate from Leuna groundwater (Germany): characterization of the degradation pathway with focus on 2-HIBA oxidation. In Proceedings of the 2nd European Conference on MTBE, pp. 47-50. Barcelona, Spain: CSIC.

Rohwerder, T., Breuer, U., Benndorf, D., Lechner, U. \& Müller, R. H. (2006). The alkyl tert-butyl ether intermediate 2-hydroxyisobutyrate is degraded via a novel cobalamin-dependent mutase pathway. Appl Environ Microbiol 72, 4128-4135.

Rosell, M., Barcelo, D., Rohwerder, T., Breuer, U., Gehre, M. \& Richnow, H. H. (2007). Variation in ${ }^{13} \mathrm{C} /{ }^{12} \mathrm{C}$ and $\mathrm{D} / \mathrm{H}$ enrichment factors of aerobic bacterial fuel oxygenate degradation. Environ Sci Technol 41, 2036-2043.

Schäfer, F., Breuer, U., Benndorf, D., von Bergen, M., Harms, H. \& Müller, R. H. (2007). Growth of Aquincola tertiaricarbonis L108 on tert-butyl alcohol leads to the induction of a phthalate dioxygenaserelated protein and its associated oxidoreductase subunit. Eng Life Sci 7, 512-519.

Schmidt, T. C., Morgenroth, E., Schirmer, M., Effenberger, M. \& Haderlein, S. B. (2002). Use and occurrence of fuel oxygenates in Europe. In Oxygenates in Gasoline: Environmental Aspects, pp. 58-79. Edited by A. F. Diaz \& D. L. Drogos. Washington DC: ACS.

Schmidt, T. C., Schirmer, M., Weiss, H. \& Haderlein, S. B. (2004). Microbial degradation of methyl tert-butyl ether and tert-butyl alcohol in the subsurface. J Contam Hydrol 70, 173-203.

Squillace, P., Zogorski, J. S., Wilber, W. G. \& Price, V. C. (1996). Preliminary assessment of the occurrence and possible sources of 
MTBE in groundwater in the United States, 1993-1994. Environ Sci Technol 30, 1721-1730.

Squillace, P. J., Pankow, J. F., Korte, N. E. \& Zogorski, J. S. (1997).

Review of the environmental behavior and fate of methyl tert-butyl ether. Environ Toxicol Chem 16, 1836-1844.

Steffan, R. J., McClay, K., Vainberg, S., Condee, C. W. \& Zhang, D. (1997). Biodegradation of the gasoline oxygenates methyl tert-butyl ether, ethyl tert-butyl ether, and tert-amyl methyl ether by propaneoxidizing bacteria. Appl Environ Microbiol 63, 4216-4222.
Uotila, J. \& Zaitsev, G. M. (2003). Variovorax strains capable of degrading methyl tert-butyl ether and their use. World Patent WO 03/ 033684 A1.

Zaitsev, G. M., Uotila, J. S. \& Häggblom, M. M. (2007). Biodegradation of methyl tert-butyl ether by cold adapted mixed culture and pure bacterial cultures. Appl Microbiol Biotechnol 74, 1092-1102.

Edited by: H. L. Drake 